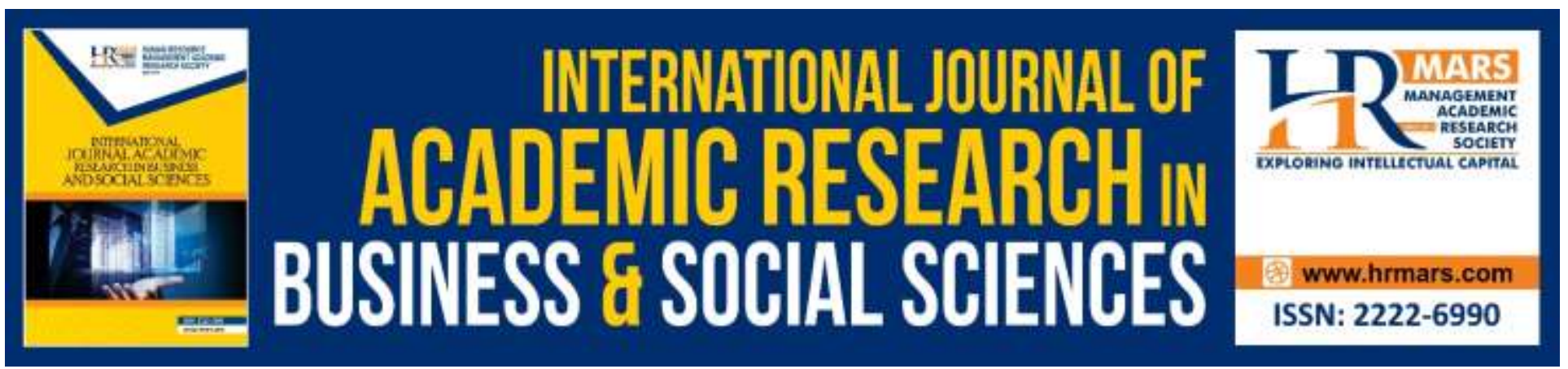

\title{
A Review on Triaging For Patients in the Emergency Department: Overview, Aims, Guideline, and Challenges
}

\author{
A. K. Hamzah, W. N. Hussein, H. N. Hussain, F. Momani, O. Zghoul, Ahmed \\ Meri, Z. T. Abdulwahhab, M. H. Jassim, M. L. Shuwandy
}

To Link this Article: http://dx.doi.org/10.6007/IJARBSS/v9-i14/6499

DOI:10.6007/IJARBSS/v9-i14/6499

Received: 22 July 2019, Revised: 17 August 2019, Accepted: 02 September 2019

Published Online: 23 September 2019

In-Text Citation: (Hamzah et al., 2019)

To Cite this Article: Hamzah, A. K., Hussein, W. N., Hussain, H. N., Momani, F., Zghoul, O., Meri, A., ... Shuwandy, M. L. (2019). A Review on Triaging For Patients in the Emergency Department: Overview, Aims, Guideline, and Challenges. International Journal of Academic Research in Business and Social Sciences, 9(14), 1-9.

Copyright: (C) 2019 The Author(s)

Published by Human Resource Management Academic Research Society (www.hrmars.com)

This article is published under the Creative Commons Attribution (CC BY 4.0) license. Anyone may reproduce, distribute, translate and create derivative works of this article (for both commercial and non-commercial purposes), subject to full attribution to the original publication and authors. The full terms of this license may be seen

at: http://creativecommons.org/licences/by/4.0/legalcode

Vol. 9, No. 14, Special Issue: Education 4.0: Future Learning, Pg. 1 - 9

Full Terms \& Conditions of access and use can be found at http://hrmars.com/index.php/pages/detail/publication-ethics 


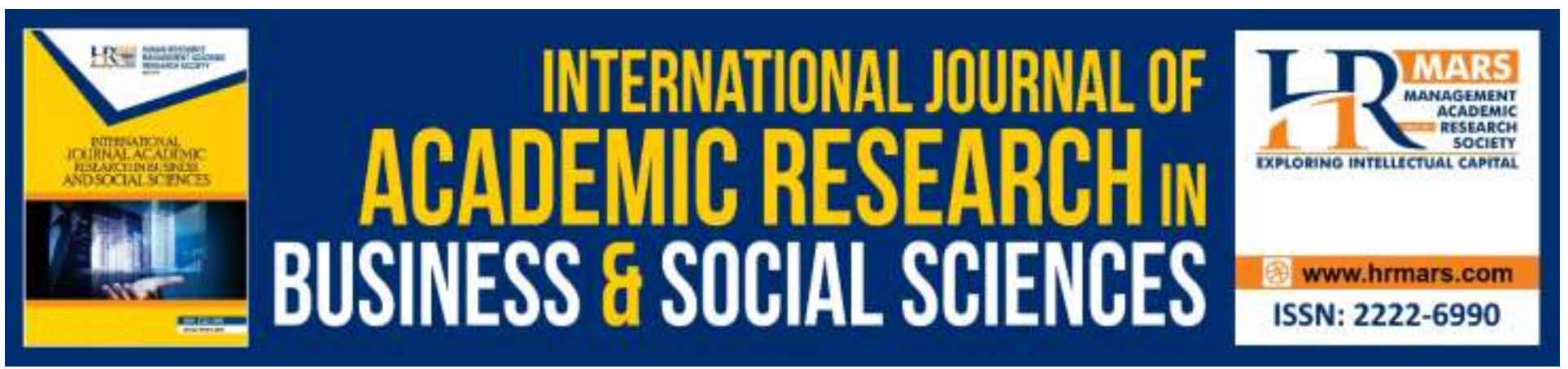

\title{
A Review on Triaging For Patients in the Emergency Department: Overview, Aims, Guideline, and Challenges
}

\author{
A. K. Hamzah ${ }^{1}$, W. N. Hussein ${ }^{2}$, H. N. Hussain ${ }^{3}$, F. Momani ${ }^{1}$, O. \\ Zghoul $^{1}$, Ahmed Meri', Z. T. Abdulwahhab', M. H. Jassim¹, M. L. \\ Shuwandy ${ }^{1}$
}

${ }^{1}$ Department of Computing, Faculty of Arts, Computing and Creative Industry, Universiti Pendidikan, Sultan Idris, Tanjong Malim, Perak, Malaysia. E-mail: nasernaser310@gmail.com, ${ }^{2}$ Department of

Mathmatics, College of education for pure science Basra University, ${ }^{3}$ Department of Computer science, College of education for pure science Basra University, ${ }^{4}$ Faculty of Information Science and Technology, Universiti Kebangsaan Malaysia.

\begin{abstract}
Congestion in emergency departments is an overall issue. Triaging includes an underlying arranging of patients who arrive at the Emergency Department (ED), keeping in mind the end goal is to organize the most emergency patients and to guarantee giving them the proper and quick healthcare needed. This study plans to survey the models, guidelines, advancement of the electronic triage procedures of the triaging frameworks. Likewise, the goals of this investigation are to experimentally investigate and show the huge of utilizing triaging in various healthcare environment, to highlight the fundamental issues in the triage framework and to open research issues that guide the researches to improve the efficiency of remote healthcare monitoring frameworks by enhancing triaging processes. Keywords: Triage, Guidelines and Standard of Triage, E-Triage
\end{abstract}

\section{Introduction}

Triage is an important task in an emergency department (ED). Triage is viewed as the rating of patient's clinical urgency (Farrohknia et al., 2011a). Rating is important to recognize the order in which patients ought to be given care in an ED when demand is high. Triage scales mean to streamline the time of patients as per the seriousness of their health condition, keeping in mind to treat the most extraordinary symptoms as fast as necessary and to decrease the negative effect on the visualization of a drawn out postponement before treatment. ED triage is a relatively modern phenomenon, introduced in the 1950s in the United States (Gilboy et al., 1999). Triage is a complex decision-making process, and several triage scales have been designed as decision Sport systems 
INTERNATIONAL JOURNAL OF ACADEMIC RESEARCH IN BUSINESS AND SOCIAL SCIENCES

Vol. 9, No. 14, Special Issue: Education 4.0: Future Learning. 2019, E-ISSN: 2222-6990 @ 2019 HRMARS

(Bullard et al., 2008) to guide the triage nurse to a correct decision. To ensure patient safety and provide quality services, hospitals should be certain that each patient entering the ED relives appropriate care at the right time. Triaging is important for patients' appraisal to appropriately anticipate the information's required for every patient and perceive abnormal vital signs.

Triage is originally from the French word trier signifying 'to sort,' is a procedure of prioritization (Bottrill et al., 2008). Indeed, it is utilized to distinguish the level of urgency of care and to treat patients in light of their triage level (Farrohknia et al., 2011b). Triage is the arrangement of arranging patients by order of treatment need in extensive scale emergencies (Jentsch et al., 2013).It is likewise the way toward surveying and organizing look after all patients present in the ED (Innes et al., 2011). Triage protocols are helpful to decide the need of patient's treatments in light of the seriousness of their conditions (Niswar et al., 2013). An important goal of triage in the ED is to recognize patients who can safely wait and the individuals who can't (Brown and Clarke, 2014). Nurses who are experienced can examine patient's health condition as well as takes note of any progressions, and decides the patient's priority for admission to the ED and the essential treatment (Seising and Tabacchi, 2013).

\section{Evaluation of the Medical Guidelines}

Guidelines are verified on the basis of environment and type of disease, as shown in Tab 1.

Tab 1 Review of Evaluation Studies for Medical Guidelines

\begin{tabular}{|c|c|c|}
\hline Ref/year & Aim & Conclusion \\
\hline$\overleftarrow{c}$ & Compare the Canadian Triage and & The Australian Emergency Mental \\
\hline 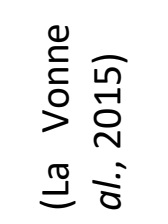 & $\begin{array}{l}\text { Acuity Scale (CTAS) protocol with the } \\
\text { Australian Emergency Mental Health } \\
\text { Triage System protocol to evaluate } \\
\text { psychiatric patients in the ED. }\end{array}$ & $\begin{array}{l}\text { Health Scale provides less } \\
\text { ambiguous mental health-specific } \\
\text { triage guidelines compared with } \\
\text { the CTAS. }\end{array}$ \\
\hline 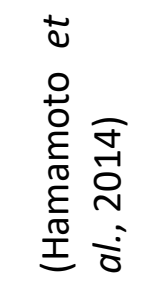 & $\begin{array}{l}\text { Measure and compare the } \\
\text { effectiveness of nursing triage before } \\
\text { and after the introduction of the } \\
\text { Japanese Triage and Acuity Scale } \\
\text { (JTAS). }\end{array}$ & $\begin{array}{l}\text { The JTAS positively affects nursing } \\
\text { triage and medical care. }\end{array}$ \\
\hline$\frac{\overline{\dot{\sigma}}}{}$ & & \\
\hline 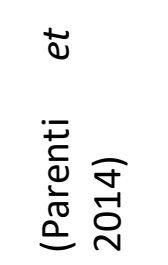 & $\begin{array}{l}\text { Conduct a systematic review to check } \\
\text { the level of validity and reliability of the } \\
\text { Manchester Triage System (MTS). }\end{array}$ & $\begin{array}{l}\text { The quality of reporting in } \\
\text { reliability and validity studies of } \\
\text { the MTS is good. }\end{array}$ \\
\hline
\end{tabular}


INTERNATIONAL JOURNAL OF ACADEMIC RESEARCH IN BUSINESS AND SOCIAL SCIENCES Vol. 9, No. 14, Special Issue: Education 4.0: Future Learning. 2019, E-ISSN: 2222-6990 @ 2019 HRMARS

\begin{tabular}{|c|c|c|}
\hline Ref/year & Aim & Conclusion \\
\hline 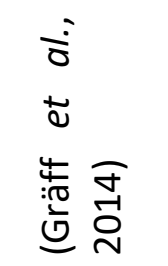 & $\begin{array}{l}\text { Evaluate the German version of the } \\
\text { MTS with the English version with } \\
\text { respect to presentation diagrams and } \\
\text { change indicators, which significantly } \\
\text { affect the assigned category. }\end{array}$ & $\begin{array}{l}\text { The German version of the MTS is } \\
\text { a reliable and valid instrument for } \\
\text { a first assessment of emergency } \\
\text { patients in the ED. }\end{array}$ \\
\hline 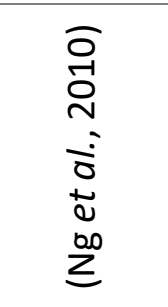 & $\begin{array}{l}\text { Compare the prioritization and } \\
\text { resource usage of the four-level Taiwan } \\
\text { Triage System and the standardized } \\
\text { five-level CTAS among ED patients. }\end{array}$ & $\begin{array}{l}\text { CTAS exhibits better } \\
\text { discrimination in ED patient triage } \\
\text { and shows greater validity when } \\
\text { predicting hospitalization } \\
\text { compared with the Taiwan Triage } \\
\text { System. }\end{array}$ \\
\hline
\end{tabular}

The main finding of this section is that researchers continue to improve existing guidelines and that numerous studies were already conducted to demonstrate the evaluation of certain guidelines in different hospitals and cities. These studies aim to improve the performance of the guidelines. No restricted guidelines should be used, and the guidelines can be improved.

\section{Review of Triage System Standards}

In this section, different triage systems are reviewed. Those systems are being used in the ED in different countries and different hospitals. The reviewed systems are demonstrated in Tab 2.

Tab Error! No text of specified style in document. State of the art triaging systems

\begin{tabular}{|c|c|c|}
\hline Triage System & Type & Description \\
\hline $\begin{array}{l}\text { Early Warning Scorecard } \\
\text { (EWS) (Christensen et al., } \\
2011 b) \text { / } 2011\end{array}$ & $\begin{array}{l}\text { Paper- } \\
\text { Based }\end{array}$ & $\begin{array}{l}\text { A simple scoring system for bedside monitoring to } \\
\text { serve as a clinical add-on using routinely collected } \\
\text { vital sign data. }\end{array}$ \\
\hline $\begin{array}{l}\text { Modified Early Warning } \\
\text { Scorecard } \quad \text { (MEWS) } \\
\text { (Zarabzadeh et al., 2013) }\end{array}$ & $\begin{array}{l}\text { Paper- } \\
\text { Based }\end{array}$ & $\begin{array}{l}\text { MEWS is a modified version of EWS. } \\
\text { Vital sign data is manually sampled and recorded. }\end{array}$ \\
\hline $\begin{array}{l}\text { Electronic Modified Early } \\
\text { Warning Scorecard } \\
\text { (eMEWS) (Zarabzadeh et } \\
\text { al., 2013) }\end{array}$ & Digital & $\begin{array}{l}\text { (eMEWS) represents a shift from paper-based } \\
\text { warning Scorecard (eMEWS) systems to electronic } \\
\text { systems. } \\
\text { eMEWS is often designed and developed around } \\
\text { the paper-based MEWS guidelines and associated } \\
\text { protocols. }\end{array}$ \\
\hline $\begin{array}{l}\text { Emergency Severity } \\
\text { Index (ESI) (Seising and } \\
\text { Tabacchi, 2013) }\end{array}$ & $\begin{array}{l}\text { Paper- } \\
\text { Based }\end{array}$ & $\begin{array}{l}\text { Designed for use in ED triage by the US } \\
\text { Department of Health \& Human Services. }\end{array}$ \\
\hline
\end{tabular}


INTERNATIONAL JOURNAL OF ACADEMIC RESEARCH IN BUSINESS AND SOCIAL SCIENCES Vol. 9, No. 14, Special Issue: Education 4.0: Future Learning. 2019, E-ISSN: 2222-6990 @ 2019 HRMARS

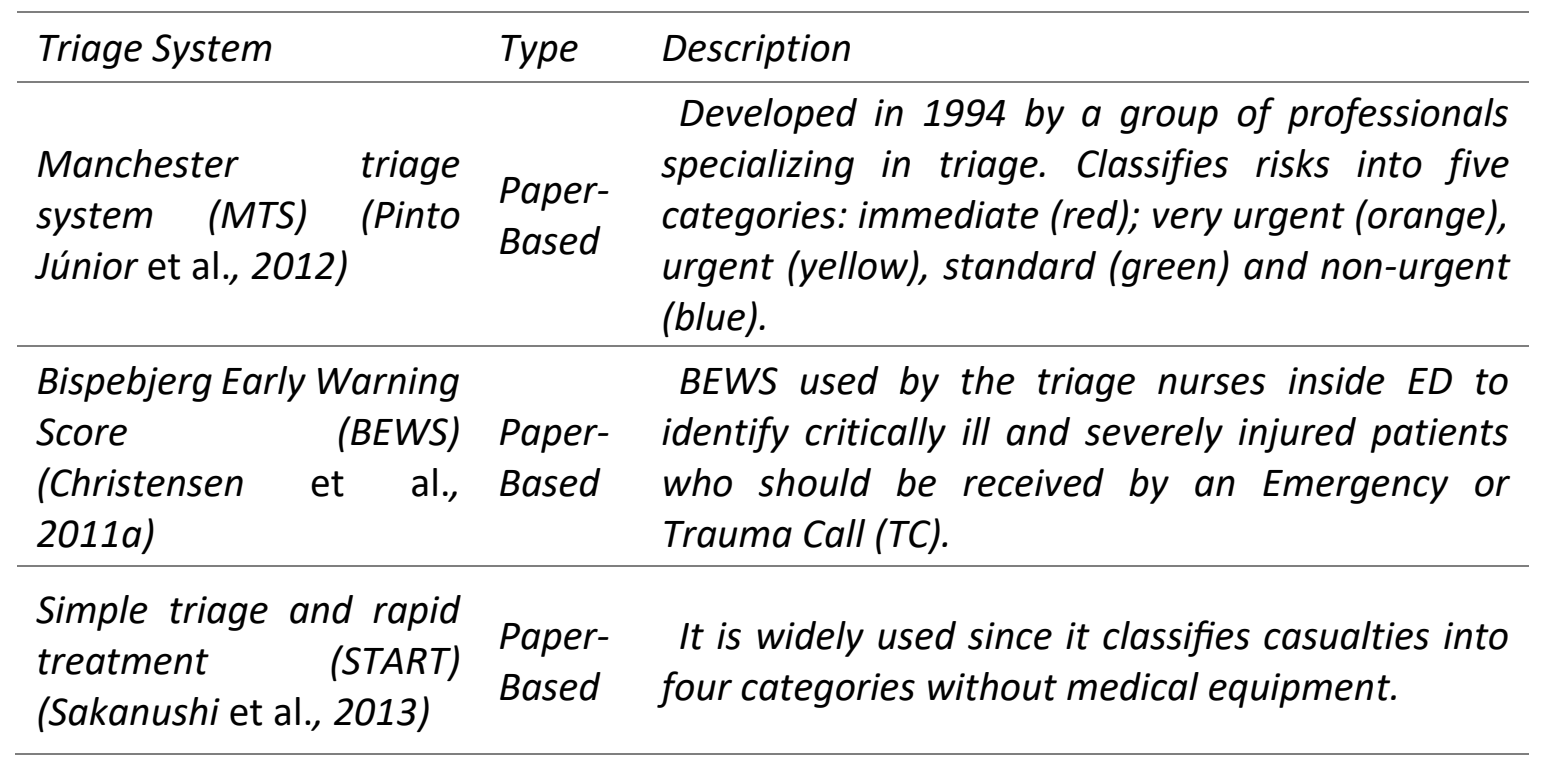

According to Tab $2 \mathrm{~s}$ six out of seven triage system that has been reviewed used paper triage, while only one used digital triage. Furthermore, the majority of these systems has been used inside ED department. The main conclusion in the section is there is a remarkable trend toward digitalization the triage system. The significance of the Emergency Department triage assessment has lead researchers to study and developed digital triage procedures based on medical guidelines. According to Krupinski and Bernard (2014), the advancement of rules and standards for telemedicine is a vital and important process that guarantees viable and safe conveyance of value healthcare. Associations, for example, the American Telemedicine Affiliation (ATA) organize the advancement of standards and rules and demonstrate that telemedicine will keep on growing as a vital and suitable strategy for enhancing access to medicinal services all through the world. In an ideal world, rules for giving healthcare services in the traditional manner and telemedicine should be standardized. However, the current guidelines serve an assortment of valuable capacities and will keep on being perceived in telemedicine. A critical part of triage is the consistency in triage basic leadership and the utilization of triage classifications.

Several factors contribute to consistency in triage decision-making (Innes et al., 2011). One of the main factors is "the number of vital signs (features) of the patient" used in triaging. Certain guidelines are also used in the ED to triage patients, as demonstrated by (Godfrey et al., 2000). The guidelines differ from one disease to another, thus indicating that no unique guidelines exist in triaging patients for all diseases. Another factor called "type of disease" also affects the accuracy of triage decision.

Electronic Triage Technique

Remote triage is a process of triaging patients using electronic devices, medical sensors, and computing algorithms based on medical guidelines (Sakanushi et al., 2013; Salman et al., 2017). Many studies were conducted on this topic. The study by Gao and White (2006) developed a triage system to develop the efficiency of emergency response. The proposed system comprises E-triage tags, base stations laptops, wearable vital sign sensors, pervasive tracking software, and personal digital 
INTERNATIONAL JOURNAL OF ACADEMIC RESEARCH IN BUSINESS AND SOCIAL SCIENCES

Vol. 9, No. 14, Special Issue: Education 4.0: Future Learning. 2019, E-ISSN: 2222-6990 @ 2019 HRMARS

assistants (PDAs) to help documentation and correspondence. Their investigation condensed designing contemplations for advances that ought to work under limitations of medicinal emergencies. Despite the advantages in the study by Gao and White (2006), several drawbacks are notable; firstly, the triage process depends on only one feature, which affecting triaging accuracy. In most cases, a patient may have two levels of simultaneous priorities. Secondly, the system does not address the scalability challenge. The ability of the server to respond to all patients' requests was not made clear. Thirdly, the algorithm, model design, and implementation of their method were not analyzed mathematically or logically. Finally, no evaluation and validation method was presented.

In the study by Jorma et al. (2013); Khalid, Pahi, \& Ahmed, (2016); Madrid, Ahmed, \& Kumar, (2019), one mobile triage system called "mTriage" was proposed to determine the applicability of the radio frequency identification technology and a "mobile triage" system in a simulated multi-casualty situation. The mobile triage exhibited the potential to contribute for the management of mass casualty situations. However, one limitation of this study is its focus on the medical personnel's opinion. The main limitation in the study by Cameron et al. (2014) is that this research was conducted in a hospital, not in a telemedicine environment. Therefore, this study is beyond the scope of our study. The study by Xiong et al. (2012), presents a general model of the application of telemedicine. The proposal of the new tele medical triage system overcomes many limitations of the current paper triage tags. The authors acknowledged that the use of telemedicine for triage in future form casualty incidents is expected to grow considerably. Nevertheless, the study has some limitations, such as; firstly, the study investigated the scope of potential use of telemedicine in disaster response, however the authors did not propose a telemedicine model. Secondly, the study lacked an efficient algorithm to extract patients' vital data, as well as a triaging algorithm. Thirdly, the implementation of the model requires various suspicions about arrival patterns in local facilities, injury types, and portrayal of different treatment procedures and time-subordinate mortality.

Finally, although the simulation was able to describe the overall medical response process (Sequence of events and resource requirements), increasingly complex models are necessary to represent complicated issues arising in reality, such as the priority issue.

the model requires various suspicions about patients' entry designs in nearby offices, injury types, and portrayal of different treatment procedures and time-subordinate mortality. In the study by Mercadal et al. (2012), a double multi-agent architecture was suggested that empowers the triage of casualties in emergency situations and the programmed updating of their health condition. The proposed scheme combines Wireless Sensor Network (WSN), an electronic triage tag, and a double multi-agent system to accomplish low cost and efficiency of the system that is not infrastructure based. Initial results of the WSN roaming by agents are presented. However, the configuration of the triage tag based on the vital signs was not addressed. Moreover, the study focuses on routing among wireless nodes, the implementation includes many assumptions.

As shown above, several techniques have been used to triage patients out of the hospital. However the latest and the most efficient one is the electronic triage technique (E-triage). According to the technical vision of the remote triage algorithm, the required triage algorithm should have the following specifications; firstly, triage patients remotely, wherever they are. Secondly, use new 
INTERNATIONAL JOURNAL OF ACADEMIC RESEARCH IN BUSINESS AND SOCIAL SCIENCES

Vol. 9, No. 14, Special Issue: Education 4.0: Future Learning. 2019, E-ISSN: 2222-6990 @ 2019 HRMARS

symptoms and features for triaging users. Thirdly, improve the guideline scores for chronic diseases through the use of sensory data and text. Finally, improve the accuracy of triaging through an efficient mathematical theory so that the triaging level is selected by an efficient algorithm and not by human opinion.

\section{Triage System Problems and Challenges}

According to the description on the triaging process explained in the previous sections, triaging systems face many challenges. Rising number of patients in Emergency departments can lead to overcrowding, which frequently results an organizational problems. Triage aims to predict the severity of disease and organize patient flow (Azeredo et al., 2015). Moreover, triaging is a complex decision-making process. Thus, several triage scales were designed to correspond to decision support systems (Seising and Tabacchi, 2013) and direct the triage nurse to a accurate decision. EDs around the world face continuous increases in patient visits (Seising and Tabacchi, 2013). Reducing the number of patients in the ED with NSCs leads to the effective management of medical resources. As the aging population will increase further, providing quality cost-efficiency care for these patients with several and complex medical conditions (Alemdar and Ersoy, 2010; Momani and Abualkishik, 2014; Seising and Tabacchi, 2013; Zughoul et al.). In the ED, the limited number of medical professionals requires the efficient exploitation of human resources to make the right decisions and leads to the need for develop automatic decision-making systems, such as those in the ED triaging process (Meri and Hasan, 2017; Seising and Tabacchi, 2013). Moreover, the number of triage nurses affects the number of patients that can be concurrently serviced at the triage desk (Yuan and Herbert, 2014).

Furthermore, Experts had argued that waiting patients should be reassessed occasionally (Claudio et al., 2014; Derlet, 2002). Since, it has been recorded that patient's situation can be changed over time, which may lead changes in patient's triage status (Claudio et al., 2011; Wolf et al., 2006). Nevertheless, this may be impossible in an understaffed or an overcrowded ED (Derlet, 2002). In fact, many hospitals and HealthCare centers only have a verbal policy on patient reassessment however nurses do not act on it because, in many cases, overcrowding keeps them busy with new patients (Claudio et al., 2011).

\section{Conclusion}

This paper provide a comprehensive insights on patient triaging systems, processes, standards, and guidelines. Besides, this paper shows the issues and challenges surround the triaging process inside and outside the hospital. Furthermore, this review highlighted the use of electronic triage, which is a process of triaging patients using electronic devices, medical sensors, and computing algorithms based on medical guidelines. A state of the art of electronic triage systems were provided in order to show the current trends and the related problems. Some researchers made suggestions towards improving the present triage systems, however, the major drawback continues to revolve around its dependency on the vital indicators originally measured by ED staff that are not followed up periodically over the critical waiting period. 
INTERNATIONAL JOURNAL OF ACADEMIC RESEARCH IN BUSINESS AND SOCIAL SCIENCES

Vol. 9, No. 14, Special Issue: Education 4.0: Future Learning. 2019, E-ISSN: 2222-6990 @ 2019 HRMARS

\section{References}

Alemdar, H., and Ersoy, C. (2010). Wireless sensor networks for healthcare: A survey. Computer Networks, 54(15), 2688-2710.

Azeredo, T. R. M., Guedes, H. M., de Almeida, R. A. R., Chianca, T. C. M., and Martins, J. C. A. (2015). Efficacy of the Manchester Triage System: a systematic review. International emergency nursing, 23(2), 47-52.

Brown, A.-M., and Clarke, D. E. (2014). Reducing uncertainty in triaging mental health presentations: Examining triage decision-making. International emergency nursing, 22(1), 47-51.

Bullard, M. J., Unger, B., Spence, J., and Grafstein, E. (2008). Revisions to the Canadian emergency department triage and acuity scale (CTAS) adult guidelines. Cjem, 10(2), 136-151.

Cameron, A., Rodgers, K., Ireland, A., Jamdar, R., and McKay, G. A. (2014). A simple tool to predict admission at the time of triage. Emergency Medicine Journal, emermed-2013-203200.

Christensen, D., Jensen, N. M., Maaloe, R., Rudolph, S. S., Belhage, B., and Perrild, H. (2011a). Low compliance with a validated system for emergency department triage. Dan Med Bull, 58(6), A4294.

Christensen, D., Jensen, N. M., Maaløe, R., Rudolph, S. S., Belhage, B., and Perrild, H. (2011b). Nurseadministered early warning score system can be used for emergency department triage. Dan. Med. Bull, 58, A4221.

Claudio, D., Bravo-Llerena, W., Okudan, G. E., and Freivalds, A. (2011). Waiting in the Emergency Department: Dynamics of Patients' Vital Signs. Paper presented at the IIE Annual Conference. Proceedings, 1.

Claudio, D., Kremer, G. E. O., Bravo-Llerena, W., and Freivalds, A. (2014). A dynamic multi-attribute utility theory-based decision support system for patient prioritization in the emergency department. IIE Transactions on Healthcare Systems Engineering, 4(1), 1-15.

Derlet, R. W. (2002). Triage and ED overcrowding: two cases of unexpected outcome. The California Journal of Emergency Medicine, 3(1), 8.

Farrohknia, N., Castrén, M., Ehrenberg, A., Lind, L., Oredsson, S., Jonsson, H., et al. (2011a). Emergency department triage scales and their components: a systematic review of the scientific evidence. Scandinavian journal of trauma, resuscitation and emergency medicine, 19(1), 42.

Gao, T., and White, D. (2006). A next generation electronic triage to aid mass casualty emergency medical response. Paper presented at the AMIA Symposium Proceedings, 6501-6504.

Gilboy, N., Travers, D., and Wuerz, R. (1999). Re-evaluating triage in the new millennium: a comprehensive look at the need for standardization and quality. Journal of Emergency

Hamamoto, J., Yamase, H., and Yamase, Y. (2014). Impacts of the introduction of a triage system in Japan: a time series study. International emergency nursing, 22(3), 153-158.

Innes, K., Plummer, V., and Considine, J. (2011). Nurses' perceptions of their preparation for triage. Australasian Emergency Nursing Journal, 14(2), 81-86.

Jentsch, M., Ramirez, L., Wood, L., and Elmasllari, E. (2013). The reconfiguration of triage by introduction of technology. Paper presented at the Proceedings of the 15th international conference on Human-computer interaction with mobile devices and services, 55-64. 
INTERNATIONAL JOURNAL OF ACADEMIC RESEARCH IN BUSINESS AND SOCIAL SCIENCES

Vol. 9, No. 14, Special Issue: Education 4.0: Future Learning. 2019, E-ISSN: 2222-6990 @ 2019 HRMARS

Jorma, J., Heli, L., Janne, E., and Ville, H. (2013). Experiences of Using a Mobile RFID-Based Triage System. Journal of Aeronautics \& Aerospace Engineering, 2013.

Krupinski, E. A., and Bernard, J. (2014). Standards and guidelines in telemedicine and telehealth. Paper presented at the Healthcare, 74-93.

Khalid, N., Pahi, M. H., \& Ahmed, U. (2016). Loosing your best talent: Can leadership retain employees? The dilemma of the banking sector of Hyderabad Sindh, Pakistan: A mediation investigation. International Review of Management and Marketing, 6(3), 608-616.

La Vonne, A. D., Zun, L. S., and Burke, T. (2015). Comparison of Canadian triage acuity scale to Australian Emergency Mental Health Scale triage system for psychiatric patients. International emergency nursing, 23(2), 138-143.

Mercadal, E., Robles, S., Martí, R., Sreenan, C. J., and Borrell, J. (2012). Double multiagent architecture for dynamic triage of victims in emergency scenarios. Progress in Artificial Intelligence, 1(2), 183-191.

Madrid, D., Ahmed, U., \& Kumar, R. (2019). Examining the Impact of Classroom Environment on Entrepreneurship Education: Case of a Private University in Bahrain. Journal of Entrepreneurship Education, 22(1), 1-8.

Meri, A., and Hasan, M. K. (2017). Assessing the Determinants of Cloud Computing Services for Utilizing Health Information Systems: A Case Study. International Journal on Advanced Science, Engineering and Information Technology, 7(2), 503-510.

Momani, F., and Abualkishik, A. M. (2014). Factors Influencing Students' Intention to Adopt Mobile Blackboard. International Journal of Science and Research, 3(5), 29-32.

Niswar, M., Ilham, A. A., Palantei, E., Sadjad, R. S., Ahmad, A., Suyuti, A., et al. (2013). Performance evaluation of ZigBee-based wireless sensor network for monitoring patients' pulse status.

Parenti, N., Reggiani, M. L. B., lannone, P., Percudani, D., and Dowding, D. (2014). A systematic review on the validity and reliability of an emergency department triage scale, the Manchester Triage System. International journal of nursing studies, 51(7), 1062-1069.

Pinto Júnior, D., Salgado, P. d. O., and Chianca, T. C. M. (2012). Predictive validity of the Manchester Triage System: evaluation of outcomes of patients admitted to an emergency department. Revista latino-americana de enfermagem, 20(6), 1041-1047.

Salman, O., Zaidan, A., Zaidan, B., Naserkalid, and Hashim, M. (2017). Novel Methodology for Triage and Prioritizing Using "Big Data" Patients with Chronic Heart Diseases Through Telemedicine Environmental. International Journal of Information Technology \& Decision Making, 1-35.

Seising, R., and Tabacchi, M. E. (2013). Fuzziness and Medicine: Philosophical Reflections and Application Systems in Health Care: A Companion Volume to Sadegh-Zadeh's Handbook of Analytical Philosophy of Medicine (Vol. 302): Springer.

Wolf, L. D., Potter, P., Sledge, J. A., Boxerman, S. B., Grayson, D., and Evanoff, B. (2006). Describing nurses' work: combining quantitative and qualitative analysis. Human Factors: The Journal of the Human Factors and Ergonomics Society, 48(1), 5-14.

Xiong, W., Bair, A., Sandrock, C., Wang, S., Siddiqui, J., and Hupert, N. (2012). Implementing telemedicine in medical emergency response: concept of operation for a regional telemedicine hub. Journal of medical systems, 36(3), 1651-1660.

Yuan, B., and Herbert, J. (2014). Context-aware hybrid reasoning framework for pervasive healthcare. Personal and ubiquitous computing, 18(4), 865-881. 